\title{
Research on Lean Marketing Management of Mobile Games
}

\author{
Yaxi Zhou \\ School of Business Administration, South China University of Technology, Guangzhou, China \\ Email: wind1992@foxmail.com
}

How to cite this paper: Zhou, Y.X. (2019) Research on Lean Marketing Management of Mobile Games. Modern Economy, 10, 86-95

https://doi.org/10.4236/me.2019.101006

Received: December 21, 2018

Accepted: January 8, 2019

Published: January 11, 2019

Copyright (C) 2019 by author(s) and Scientific Research Publishing Inc. This work is licensed under the Creative Commons Attribution International License (CC BY 4.0).

http://creativecommons.org/licenses/by/4.0/

\begin{abstract}
The mobile gaming industry has become more popular in the near future, and mobile game products of hundreds of millions of users have repeatedly appeared. At the same time, the internal and external marketing environment of the mobile game industry is undergoing many dramatic changes. The emergence of emerging channels and the diversification of advertising products have placed higher demands on the marketing links of mobile game distribution. Under the complicated market competition pattern, exploring the new era of mobile game marketing strategy has become a top priority for mobile game industry managers. This thesis sorts out the theory of lean manufacturing and lean management, builds a lean ideology system, and explores the introduction of "lean marketing" derived from the above theory into the mobile game industry marketing theory, and expands the application scope of lean marketing theory. Based on this, the domestic mobile game industry under the guidance of lean thinking, clears user needs, leanly matches user groups, and strives to eliminate non-value-added activities and wasteful behaviors in marketing activities, rationally selects channels, accurately places advertisements, and continuously optimizes feedback. Help the original mobile game marketing to be lean and professional.
\end{abstract}

\section{Keywords}

Lean Marketing, Mobile Game, Emerging Channels, User Needs

\section{Introduction}

The article is organized as follows: first, we will systematically introduce the origin of lean marketing ideas and its relationship with lean production. Then we will analyze the marketing status and shortcomings of the domestic mobile game industry, and use the theoretical results of lean marketing to combine the cur- 
rent situation of the mobile game industry to derive the lean marketing method of the mobile game industry.

The theory of lean production was born from practice. Sixty years ago, Japanese manufacturing industry summarized this new production mode while improving the efficiency of enterprises. The American Society of Production and Inventory Management Dictionary (Cox and Blackstone, 1998) provides a simple definition of lean enterprise and lean manufacturing [1]. "Lean" is the identification of all non-value added activities that exist in business operations. We need to identify and eliminate it. This definition makes people realize that "lean" is equated with "eliminating waste." But "eliminating waste" is only a method, not the purpose of lean production, and it is even less able to reflect the whole idea of lean [2]. Chinese scholars Li Juan and Liu Xu's book "Lean Assembly Management" defines "lean production" as follows: "Lean production is a change in system structure, personnel organization, operation mode and market supply and demand, so that the production system can be quickly adapted to the changing needs of users, and make all the useless and redundant things in the production process streamlined, and finally achieve the best results in all aspects of production including market supply and marketing [3]."

In theory, another result of the lean production process is the conclusion of lean thinking. James Womack and Daniel Jones's "Lean Thoughts" define lean thinking, including five basic concepts, values, and lean thinking [4]. The value of an enterprise product service is considered to be determined only by the end user. Second, the value stream refers to all activities that give value from raw materials to finished products, and seeks the overall best of the whole process according to the position of the end user [5]. Third, the flow, lean thinking requires the flow of activities to create value, and Lean takes all stagnation as a waste of the enterprise. Fourth, pull, let users pull production as needed, instead of forcing users to the product service that users do not want, to ensure that users get product service at the required time [6]. Fifth, perfection, includes a sense of customer satisfaction, error-free production services and continuous improvement of the company itself. The above five basic concepts are the theoretical foundations for the practical application of lean management to guide lean management and lean marketing.

Marketing is the marketing activities of the company. There are many definitions of marketing, but different people have different emphasis on marketing, some focus on trading, some focus on relationships, and some focus on creation. In general, the marketing process is the process of the market activities that the company meets the needs of customers [7].

As a brand-new concept, lean marketing is the extension and innovation application of "lean thinking" in the field of marketing. Lean theory is a theory summed up from production practice. This production practice fully takes into account the needs of customers and the actual sales situation in process management [8]. For example, the goal of just-in-time production, pull system kan- 
ban, value chain management, and total quality management in lean manufacturing kits is very much focused on the promotion of sales effectiveness [9]. It can be seen that the expansion and application of lean theory in the marketing process is in line with the original intention of lean production.

However, the current theoretical research on lean marketing is still relatively rare, and the definition of lean marketing is rare in various dictionaries of marketing. Lv Jianzhong's book "Lean Management Mainstream Management Model of the First Century" defines "in the right place, at the right place, with appropriate promotion, to the right customer, to the customer, Providing its appropriate customer benefits, that is, within the appropriate time, space, goods, etc., the company's marketing activities meet the willingness and willingness of the appropriate customers to obtain the customer's satisfaction. It is the lean marketing strategy [10]." Willing to try to give such a definition, the so-called lean marketing, under the guidance of lean thinking, to quickly meet the diversified needs of customers, strive to identify and eliminate the non-value-added activities existing in marketing activities, and continue to improve the marketing system, A marketing strategy that pursues the maximization of marketing value [11]. In the system model of lean marketing, customers should be at the core of the entire system.

Therefore, the core idea of the "lean marketing strategy" is to eliminate the waste that does not generate value in the process, and to pursue the marketing cost to the most effective and valuable place, so that the investment income ratio is as high as possible. Lean marketing emphasizes the rational allocation of resources, that is, the concentration of key resources to target markets and major customers [12]. So sum up the characteristics of lean marketing, there are four main:

\section{Quickly meet customer needs}

Lean marketing emphasizes that all activities of the company must focus on creating value for customers while emphasizing the concept of time. The implication of "just-in-time" thinking on lean marketing is to respond quickly to changes in various needs while meeting the individual requirements of customers with high quality and low cost [13]. First of all, listen to the customer's voice and understand the customer's requirements.

Guided by customer needs, multi-channel communication is used as a means to meet customer needs and create value for customers. On the basis of inspecting lean thinking, we will satisfy customers' needs as much as possible and as quickly as possible, so as to cultivate repeated purchases of loyal customers to convert customer requirements into specific product characteristics and management control objectives. The components of the company maintain a long-term relationship with customers with quality and efficient services [14].

\section{Targeting effective markets}

Lean marketing emphasizes the effectiveness of the target market, pays attention to the input-output ratio of marketing activities, and eliminates the ineffective input of blind marketing with no focus. In order to seek high-quality 
long-term development, enterprises should not simply pursue market share, but should emphasize the possession of effective markets, with a view to the management effectiveness and long-term sustainable development of enterprises [15].

\section{Sublimate people's ideas and continue to learn}

The essence of the development of the enterprise is the development of the employees. The essence of the marketing activities is the marketing of the people. The employees are the decisive factors for the operation of the enterprise. The ideas of the whole automation and unmanned factories that have been proposed have long since disappeared [16]. Therefore, lean marketing believes that employees should be fundamentally respected and employees should be developed, emphasizing teamwork, teamwork, quality of personnel, and continuous learning of organizations.

\section{Integrated resource allocation}

Lean marketing emphasizes the flexibility of the organization and the optimization of business units, enabling flexible allocation of resource combinations and striving for the best marketing results with the lowest marketing costs [17]. Strive for perfect lean marketing to implement the whole process management control of marketing factor integration, and believe that the marketing process has started from the product concept design stage until the end of the after-sales service.

\section{Analysis of Marketing Environment in Mobile Game Industry}

In 2018, a phenomenon-level mobile game drove the rhythm of the fragmentation time of the crowd. The outbreak of the mobile game market also made mobile games become the competition of many industries. The jewels have also led to the mobile gaming industry becoming a competitive and fierce industry. However, since the mobile game industry is an emerging industry, there is little research on this industry in the academic field. Therefore, this paper is aimed at the marketing of the mobile game industry. In the following, we will cover the scope, market composition and marketing of the mobile game industry. Ways, the status quo of the marketing environment, problems and other aspects of the analysis of the marketing environment.

As shown in Figure 1, the main chain of mobile game is R \& D, distribution, and user. R \& D refers to mobile game developers, which are mainly responsible for research and development of mobile game content and long-term optimization of mobile game content and provide technical guidance in the post supply chain. The issue mainly refers to the products developed by the agent mobile game developers to market, introduce users, and generate revenue. Mobile game publishers need to use channels to introduce users in the process of proxy products. Channels refer to traffic portals with user-based channels. The specific channels are mainly divided into hard core alliances, system stores, third-party application stores, super APPs, and vertical channels. Hardcore alliances and system stores account for a large percentage of the market's traffic. 


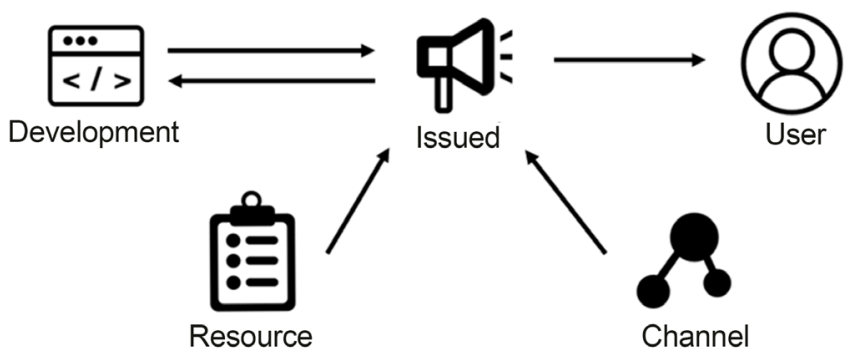

Figure 1. Mobile game industry marketing component.

Shown in Figure 2 is the mobile game traffic (user) billing generation process, which is the entire marketing refinement process of the mobile game. First, the channel side has its own users. The game display of these users can be in the form of native ads, lists, banners, etc., and then the user will have a certain probability to generate clicks, and then click to jump to the download page, then There will be certain users to install and activate, and then there will be registration behavior. When the user downloads and installs a game, the issuer counts it as an active user, that is, successfully acquires a user. Channels have different ways of charging for this process. There are three main ways of cooperation between the issuer and the channel. The first method is called the intermodal mode, that is, when the channel attracts a valid user, the user belongs to the channel and belongs to the exclusive user of the channel. When the subsequent issuer of the pipeline is divided into the channel. The second method is a pure advertising model. This mode is a result-free cooperation. The channel does not need to be responsible for the consequences of the advertisement. The issuer uses the resources of the channel to purchase the advertisement. This kind of cooperation is generally used for the cooperation. The brand is promoting. The third type is the most widely used method nowadays. It is generally called the purchase quantity, that is, the purchase flow. Since it is a purchase, there must be a purchase method. The difference in the main methods is issued after the channel is pulled by the issuer. The main method used by the party to calculate the remuneration, the main way can be explained by the flow rate generation method in Figure 2. For example, the commonly used CPA mode is how many users are used to pull the game for the game, and how much is the payment method for each user. Of course, there is also a CPM model, that is, how many times the channel displays a thousand times to pay, this method is more conducive to the channel, because the channel does not need to be responsible for the effect of the display, CPA calculations need to be responsible for the effect, if the effect is not good The advertising revenue of the channel will be greatly reduced, and the user will be bothered. After all, the user does not come in to see the advertisement. Of course, there are models such as CPC and CPI in the process, and the process is similar.

Recently, due to fierce competition in the mobile game industry, technical barriers have declined, and small groups or new companies have entered the mobile game industry. The number of mobile games entering the market has 


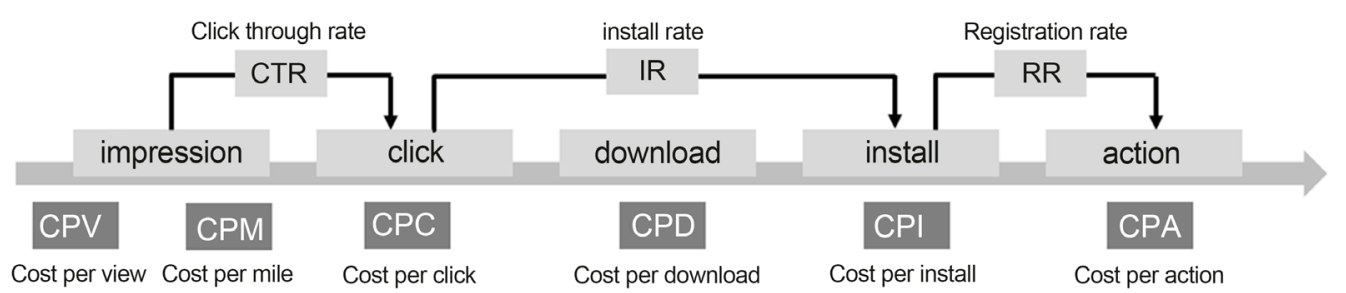

Figure 2. Mobile game industry marketing component.

been increasing and the quality has been continuously improved. This is fierce competition within the industry. From the perspective of the external market, due to the increasing promotion of smart phones in China, the cost of electronic hardware has decreased, and the price of smart phones has dropped. The proportion of Chinese people owning smart phones has been quite high, and fewer new users are added each year. This means that the cost of acquiring new users of mobile games is constantly increasing, because old smartphone users generally have better user habits for games, and will not easily select new games, resulting in a relatively high cost of acquiring them. Both internal and external factors have pushed up the cost of acquiring users in the mobile game industry. For example, active game products, such as the cost of acquiring users of the werewolf killing products, are 10 to 15 yuan per active user, which was only five yuan a year age. Under this circumstance, how to seek a better mobile game marketing method and reduce the user acquisition cost has become the focus of research and breakthrough in the industry.

\section{Analysis of Lean Marketing Strategy in Mobile Game Industry}

In the last chapter, we analyzed that due to the development of the industry and the changes in the market, the user acquisition cost of the mobile game industry continues to push up, but this also reflects the big flaws in the mobile game industry marketing model, which can only be saved through constant money. Ways to get users, then, let's analyze what is the specific problem of marketing in the mobile game industry today.

\section{Disposal price and method confusion}

Since the channel and the issuer are the seller's market in the supply and demand relationship, the issuer's demand for the channel is too large, and the channel has a certain number of users [18]. Therefore, the channel has pricing power in the supply and demand relationship, so they can define the purchase according to their own needs. Volume delivery methods and market-based competitive buying prices, which led to many channels using similar auctions to buy and sell traffic, due to the high profit margin of some mobile games, which led some mobile game companies to use rough buying Ways to deliver, regardless of the specific channel, regardless of the specific price and method, as long as there is traffic, take money, such as "Eternal Era" mobile games use this kind of delivery, which also pushed the industry to a certain extent The user cost has 
upset the industry rules.

\section{Unreasonable channel selection}

There are many types of mobile games, which also lead to large differences in the user groups of various types of mobile games. For example, the user group of "Yin Yang Shi" has obvious secondary tendency, and the user portraits are generally 18 to 30 years old, and most of most users are women or white-collar workers. Then when we put this game, the channel selection should choose the channels that these users often go, but in fact, many traffic is now in the head channel, such as App Bao, WeChat, etc., which will lead to the issue company. Regardless of whether the channel user attribute is consistent with the game itself, only the channel with larger traffic will be selected, because this can guarantee the number of users to be introduced to a certain extent, but if the user attribute is inconsistent with the game, it is easy to cause the user to lose.

\section{Blurred marketing strategy}

Although there are certain strategic customizations for the game issuance within the issuing company, due to the change of the market environment, insufficient information acquisition, insufficient preparation time of the game, etc., it is easy to make the marketing strategy less stipulated, and the self-determination is worse. The same is true for the same type of game, which will also make the same product use the same marketing method on the market, which will inevitably push up the user acquisition cost.

\section{Attracting users in a single way}

The conventional way of attracting users in the existing channels is relatively simple. Generally, there are only simple methods such as list, banner, video advertisement, and native advertisement. These methods are obviously insufficient for users, even in a certain way. To a certain extent, the user has already formed an interruption, so that the user is intrinsically contradicting such a way, and the game released in this way is a poor quality game for making money.

We have summarized the reasons for the high cost of users in the mobile game marketing process and the shortcomings of the existing marketing methods. In the following, we will introduce the idea of lean marketing into the marketing process of the mobile game industry, and analyze the above problems one by one. Optimize and introduce relevant cases for supporting.

\section{Lean of marketing factor combinations}

Involving systemic marketing innovation, it is generally necessary to use McCarthy's marketing 4P (product, price, promotion, distribution) basic theory as a conventional weapon for static analysis of marketing systems. However, in the analysis of the mobile game industry, it is different from the traditional marketing method. The promotion is not obvious in the marketing chain of the entire mobile game industry. Therefore, in the following analysis, we mainly use products, prices and distribution as the mobile game industry. The marketing mix can also be understood as the three basic components of lean marketing strategy implementation or mobile game industry marketing product value.

\section{Marketing products lean}


The lean product of marketing products is based on the needs of users, creating boutiques to meet the needs of users, and thus creating new user needs. Mobile game industry advertising products have channel dependence, that is, the existence of advertisements depends heavily on the types of channels and the product characteristics they can provide. Therefore, the relevance of advertising products and channels and products must be fully considered in the design of marketing advertising products. The channel itself has certain attributes, such as the betta channel. Because it is a live broadcast platform that starts from the game, its users have strong competitive attributes and younger characteristics. In this way, this factor should be taken into consideration when arranging mobile game advertisements in this channel. From planning and positioning to production, packaging, and layout, we must fully consider the connection with users and channels. The mobile game industry is at the forefront of the creative industry, and creativity is also the soul of advertising, so practitioners must always use the eyes of discovery to explore the blue ocean of competition. The types of marketing products must follow the rules of the product life cycle, adapt to the market demand, and break through from the "homogeneous" mobile game marketing products of thousands of people.

\section{Channel resource integration linkage}

From the perspective of lean marketing, integrated resources can be better utilized in the construction of channel products. Since channel users have certain channel attribution, it is better to create in-game linkage products for specific channels. The linkage idea can better integrate channel resources. Moreover, by continuously constructing interactions with the channels, it is also possible to construct a mindset associated with the channels for the users, so that the channels are exclusive to the same type of competing games. For example, Tencent's "cross-fire mobile game" is a custom-made weapon for OPPO app store users, in-game set cards and so on. "Bouncing Ballroom" also created exclusive props for the 4399 channel. Of course, not only unilateral games provide resources for channels, but also channels can also feed back games to a certain extent. As a resource exchange, for example, channels can be used for games to hold sweepstakes or sign-on VIP events. This kind of activities after integrating resources can often get better results.

\section{User-oriented}

There is an important theoretical basis in lean marketing, which is to quickly meet customer needs, how to quickly meet the needs of mobile game users, the first thing that needs to be done is to accurately determine users, and also aim at effective markets, so lean marketing is a coherent system. When we are thinking about how to target an effective market, we are meeting user needs. The user needs of different channels are also inconsistent. For example, the users of the app store, they enter the app store itself to find the app they need, so if you use the leaderboard or banner way, the user is acceptable because you are to some extent Meet their needs. But now the app store is characterized by the rise of 
content, such as the tappap channel, which is to attract users with credible content recommendations as the main selling point, and active users quickly broke through 5 million. This again proves the importance of meeting the needs of users. The content can make users better understand the content and quality of the game, help them make choices, and inevitably allow more users to choose similar marketing methods. More important to target an effective market is the choice of channels, which is the choice of distribution. Different channels are not only different in the user attributes mentioned earlier, but also more, whether the channel type is suitable for this type of game. For example, the military channel may not be suitable for the content of the second element, and the channel will not accept it. Channel-type ads can seriously disrupt their own users and interfere with users.

\section{Delivery method and price lean}

The mobile game traffic market has a variety of transaction methods and prices, and the quality of the traffic they bring is the same. In the past, game releases were large-scale and extensive purchases, which led to the continued increase in user costs mentioned above. Therefore, when the user cost reaches a bottleneck, how to optimize the traffic purchase method, that is, the delivery method becomes an aspect of the mobile game industry marketing. The first is the choice of methods. If you are more confident about the appeal of your game users, you can choose CPM similar methods, which can display your products in front of users. When your product or ad conversion rate is high, these methods can also get better returns. There are many similar methods. Different delivery methods and price choices have different effects. Therefore, it is very important to integrate the information and resources of all purchase channels, that is, the integrated resource allocation mentioned in lean marketing.

\section{Conclusions}

The mobile game industry marketing of internal and external troubles is standing in the watershed of the industry. In the past, the rough buying and intermodal methods have not been able to cope with the complicated market environment. In order to seek new marketing methods, many manufacturers have tried more new methods, such as user demand orientation, systematic selection of channel purchases, content to marketing products, etc., but these methods all reflect the idea of lean marketing, which also allows researchers to see that lean marketing can make a follow-up development for the mobile game industry. On the basis of summarizing the development of lean marketing theory, the author combs the marketing status of mobile game industry, and gives a brief analysis of the marketing strategy of mobile game industry under the guidance of lean marketing.

At present, the academic research on lean marketing is very limited, and there are still many specific contents to be improved. As the extension and innovation of "lean thinking" in the field of advertising and marketing, mobile game indus- 
try marketing cannot completely copy the specific practices of the manufacturing process, and it is not necessary to stick to fixed routines and models, but it must implement "lean thinking". The essence of the content, always uses a lean idea to solve the problem. At the same time, I hope this article can make a little contribution to the development of mobile game industry marketing.

\section{Conflicts of Interest}

The author declares no conflicts of interest regarding the publication of this paper.

\section{References}

[1] Albarran, A.R. (1996) Media Economics-Understanding Markets, Industries and Concept VII. Iowa State University Press, Ames.

[2] Blumenthal, H.J. and Goodenough, O.R. (1998) This Business of Television. Billord Books, New York.

[3] Croteau, D. and Hoynes, W. (2001) The Business of Media. Pine Forge Press, London.

[4] Womack, J.P. and Jones, D.T. (2009) Lean Thought. Mechanical Industry Press, Beijing.

[5] Drew, J., McCallum, B. and Rogenhof, S. (2007) The Way of Lean. Mechanical Industry Press, Beijing.

[6] Lv, J.Z., Wang, Y. and Cao, L.F. (2009) Lean Management, the Main Management Model of the 21st Century.

[7] Levinson, W.A. and Leyick, R.A. (2005) Integrated Method for Lean Enterprise to Minimize Waste.

[8] Hou, G.S. and Wang, W. (2004) Top Ten Management Ideas Affecting the Future of Chinese Enterprises. China Textile Publishing, Beijing,

[9] Pan, J. (2009) Lean Service. Mechanical Industry Press, Beijing.

[10] Liu, C., Xue, S. and Ling, X.Y. (2007) Lean Six Sigma Actual Combat. Xuelin Press, Shanghai.

[11] Li, J. and Liu, X. (2006) Lean Assembly Management. China Metrology Publishing House, Beijing.

[12] Institute of Advertising, Communication University of China (2008) New Media Radiance.

[13] Drucker, P. (2006) Management Challenges in the 21st Century. Mechanical Industry Press, Beijing.

[14] Shengji, P. (2003) The Fifth Practice. Guo, J.L., Trans. Renmin University of China Press, Beijing.

[15] Naichi, N., Naichi, O., Liu, C., et al. (2016) On-Site Management. Machinery Industry Press, Beijing.

[16] Zhu, C.Y. (2004) Media Marketing Management. Nanfang Daily Press, Guangzhou.

[17] Tang, S.D. and Li, B. (2009) Research on TV Industry Management with Chinese Characteristics. China International Broadcasting Press, Beijing.

[18] Qian, X.W. (2008) Contemporary Media Management. Zhongshan University Press, Guangzhou. 